(c) American Dairy Science Association, 2005.

\title{
Interactions in Biofilms of Lactococcus lactis ssp. cremoris and Pseudomonas fluorescens Cultured in Cold UHT Milk
}

\author{
J. Kives, D. Guadarrama, B. Orgaz, A. Rivera-Sen, J. Vazquez, and C. SanJose \\ Departamento de Nutrición, Bromatología y Tecnología de Alimentos, \\ Universidad Complutense de Madrid, 28040, Madrid, Spain
}

\begin{abstract}
Three Lactococcus lactis ssp. cremoris isolates from refrigerated bulk raw milk were cultured separately and in association with a known psychrotrophic dairy Pseudomonas fluorescens strain, in skim UHT milk for $72 \mathrm{~h}$ at $7^{\circ} \mathrm{C}$, to determine mutual influences in both the planktonic and biofilm phases. Two levels of inoculum of each culture partner were combined. Protocooperation and commensalism cases were found, all of them in the biofilm phase. Type and intensity of the interactions depended on Lactococcus strain and on the cell density of each partner. Maximum enhancement of attachment was observed to be approximately 100 -fold for P. fluorescens and 20,000-fold for one of the L. lactis strains. Confocal scanning laser microscopy images show compact masses of Pseudomonas trapping lactococci cells in cooperative biofilms.
\end{abstract}

(Key words: psychrotrophic, biofilm, Lactococcus, Pseudomonas)

Abbreviation key: CSLM = confocal scanning laser microscopy.

\section{INTRODUCTION}

In refrigerated raw milk, Pseudomonas spp., specifically $P$. fluorescens, can be considered the specific spoilage organism (Huis in't Veld, 1996). This species is the most numerous and fastest growing bacteria in cold raw milk, and cause off-flavors largely due to extracellular proteinases and lipases. Other psychrotrophs are commonly found in raw milk (Champagne et al., 1994; Sørhaug and Stepaniak, 1997), including gram-positive bacteria such as Bacillus and Listeria. Some Lactococcus lactis strains have been reported to be psychrotrophs (Hamasaki et al., 2003), although they received little attention as such. Raw milk is usually rich in lactococci. In good quality cheese-making milk, lacto-

Received May 18, 2005.

Accepted August 1, 2005.

Corresponding author: Carmen SanJose; e-mail: serran@vet. ucm.es. cocci counts were found to be second only to those of Pseudomonas (Desmasures et al., 1997). Both genera have been reported to dominate the microbiota in downgraded Danish bulk tank milk (Holm et al., 2004). Notwithstanding, selected L. lactis ssp. lactis and cremoris are extensively used as mesophilic starters for cheese and butter production. The wild strains also have technological interest.

From an ecological point of view, $P$. fluorescens and L. lactis ssp. cremoris, when contaminants in raw milk, usually live in different niches; Pseudomonas are aerobes, non-lactose utilizing, and frequently psychrotrophic, whereas lactococci are lactose-utilizing anaerobes, and so far considered poor psychrotrophs. However, lactococci can also grow aerobically and some strains grow well at temperatures of $7^{\circ} \mathrm{C}$ and below.

In raw-milk holding equipment, 2 distinct but connected phases are available for microbial growth: the liquid phase, in which planktonic cells proliferate, and the solid/liquid interface (i.e., liquid-covered equipment walls), where cells can attach and form biofilms (Wong and Cerf, 1995; Somers et al., 2001). Each phase constitutes a unique habitat, and cells can move from one to the other, depending on growth stage, nutrient availability, and flow shear forces (Stoodley et al., 2002). The environment inside the biofilms is anaerobic, with slow diffusion rates for gases, substrates, residues, and secondary metabolite molecules. Ecological relationships between species or strains are thus likely to be different in the liquid and the biofilm phases of raw milk.

As Pseudomonas are the specific spoilage organisms of refrigerated raw milk, changes in their growth rate and spoilage activity are useful in predicting shelf life (Gram et al., 2002). Here, we present such a case due to a frequent partner, the lactococci. The outcome of the interaction with Pseudomonas on psychrotrophic lactococci could also have an influence on maintaining quality.

To identify the ecological relationships between psychrotrophic Pseudomonas and Lactococcus in cold milk, batch binary cultures in UHT-sterilized skim milk were used as model systems. Pseudomonas fluorescens B52 was combined with 3 L. lactis ssp. cremoris strains 
at 2 different initial levels. Final planktonic and biofilm counts of binary cultures were divided by those of the same strain and inoculum level at monocultures, to represent either growth enhancement or impairment as a result of the association. Confocal scanning laser microscopy (CSLM) images of representative binary cultures were obtained.

\section{MATERIALS AND METHODS}

\section{Strains}

Lactococcus strains were isolated from refrigerated bulk raw milk with high microbial load. Serial dilutions of the milk in peptone water (Oxoid, Basingstoke, UK) were plated on M17 agar (Oxoid), to be incubated under anaerobiosis at $32^{\circ} \mathrm{C}$ for $48 \mathrm{~h}$, for preliminary enrichment in lactococci. Some of the gram-positive, catalasenegative cocci colonies were picked at random from enrichment plates, purified by subculturing, and identified using API 50 CHL strips (BioMérieux, Marcy-l'Etoile, France) and partial 16S rDNA analysis (Centraalbureau voor Schimmelcultures, Utrecht, The Netherlands) as L. lactis ssp. cremoris. Pseudomonas fluorescens B52 was originally isolated from cold raw milk (Richardson and Te Whaiti, 1978). All strains were stored at $-20^{\circ} \mathrm{C}$.

\section{Cultures}

Frozen Lactococcus strains were transferred to de Man, Rogosa, and Sharpe broth (Oxoid) and incubated at $30^{\circ} \mathrm{C}$ for $12 \mathrm{~h}$. Pseudomonas were precultured in mineral medium (McKellar and Cholette, 1984 ) at $21^{\circ} \mathrm{C}$ for $24 \mathrm{~h}$. Cells were harvested by centrifugation at 4000 $\times g$ for $10 \mathrm{~min}$, and were washed twice with the mineral medium. Dilution with the original medium adjusted the 2 inoculum levels, referred to here as low and high, to obtain approximately $10^{3}$ and $10^{5} \mathrm{cfu} / \mathrm{mL}$, respectively, in UHT skim milk. Single strain cultures at each level of inoculum were used as controls. Four types of binary cultures were run for each Lactococcus strain in association with Pseudomonas, combining the 2 levels of inoculum for each organism. Biofilm formation was studied on single-use $22-\mathrm{mm}^{2}$ thin, borosilicate glass coverslips; 16 coverslips were held vertically by marginal insertion into the narrow radial slits of a Teflon carousel platform (6.6-cm diameter) and its lid, both assembled to an axial metallic rod, for handling. Coverslips, carousel, and the covered $600-\mathrm{mL}$ beaker were heat-sterilized as a unit, before aseptically introducing $55 \mathrm{~mL}$ of UHT milk with the corresponding inocula. The system, exposing about $4 \mathrm{~cm}^{2}$ of available attachment surface for each milliliter of culture liquid, was incubated at $7^{\circ} \mathrm{C}$ in a rotating shaker. Final $\mathrm{pH}$ in all cul- tures remained naturally above 6 . After $72 \mathrm{~h}$, duplicate samples were taken of both planktonic and coverslipattached cells to be plated. Before removal of the biofilm using a swab dipped in sterile peptone water, weakly attached cells were removed from the coverslips by carefully rinsing in sterile $0.9 \% \mathrm{NaCl}$. Pseudomonas fluorescens counts were obtained after plating in Pseudomonas selective agar (Oxoid), incubating for $48 \mathrm{~h}$ at $32^{\circ} \mathrm{C}$. Those of Lactococcus were obtained from M17 agar plates under anaerobiosis, also after $48 \mathrm{~h}$ at $32^{\circ} \mathrm{C}$. All cultures were reproduced 3 times.

\section{Statistical Analyses}

Analysis of variance of the association effect was performed on planktonic and biofilm counts of P. fluorescens and L. lactis, using SPSS Win 9.0 software (SPSS Inc., Chicago, IL). Significant differences were assessed by Tukey's test at $P<0.01$ using the same program.

\section{CSLM Biofilm Images}

For microscopic observation, coverslips were rinsed in $0.9 \% \mathrm{NaCl}$ and stained in the dark, at room temperature, first with $100 \mu \mathrm{g} / \mathrm{mL}$ Texas Red-X conjugate of wheatgerm agglutinin (Molecular Probes, Eugene, OR) for $10 \mathrm{~min}$ (selectively binding to gram-positive bacteria, and appearing red) and then with $0.25 \% 4^{\prime}, 6$-diamidino-2-phenylindole dihydrochloride solution (Mo-

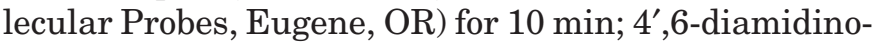
2-phenylindole dihydrochloride is an unspecific nucleic acid dye, giving blue stain to both gram-negative and gram-positive bacteria.

Confocal scanning laser microscope images were obtained using a TCSSP 2 model (Leica Lasertechnik, Heidelberg, Germany), using a $63 \times$ lens. Displayed images were processed with IMARIS software (Bitplane AG, Zürich, Switzerland).

\section{RESULTS AND DISCUSSION}

\section{Monocultures}

Comparison of planktonic counts of $P$. fluorescens at low $\left(10^{3} \mathrm{cfu} / \mathrm{mL}\right)$ single inoculum cultures (Figure 1A, white bars) showed a faster growth rate than those starting with a high inoculum level $\left(10^{5} \mathrm{cfu} / \mathrm{mL}\right.$; Figure $1 \mathrm{C}$, white bars), suggesting that at $72 \mathrm{~h}$ and $7^{\circ} \mathrm{C}$, cells were entering stationary phase. In biofilms, low inoculum cultures yielded $10^{4} \mathrm{cfu} / \mathrm{cm}^{2}$, whereas high inoculum cultures yielded $10^{6} \mathrm{cfu} / \mathrm{cm}^{2}$. A 100 -fold higher proportion of the total cells were located in biofilms in advanced growth cultures. 

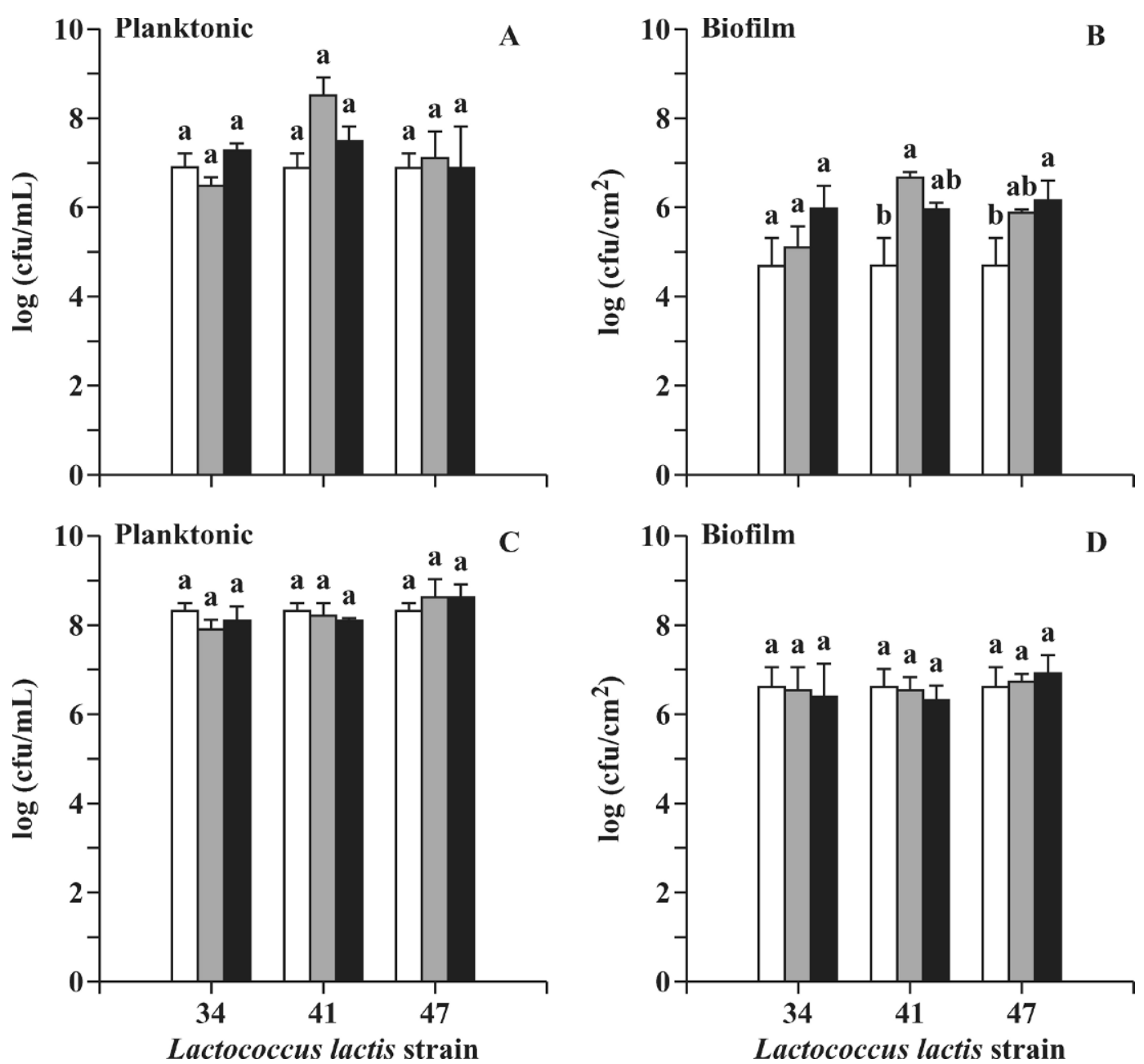

Figure 1. Pseudomonas fluorescens B52 counts (in UHT milk $7^{\circ} \mathrm{C}$ for $72 \mathrm{~h}$ ) in pure cultures (white bars), or cocultured with Lactococcus lactis (strains 34, 41, or 47), with either low (gray bars) or high (black bars) inoculum levels. A) Planktonic counts and B) biofilm counts using low inoculum of $P$. fluorescens; C) planktonic counts and D) biofilm counts using high inoculum of $P$. fluorescens. Error bars represent the confidence interval for the mean $(\mathrm{n}=3),{ }^{\mathrm{a}, \mathrm{b}}$ Values within the same bar group with different letters are significantly $(P<0.01)$ different.

Single low inoculum cultures of L. lactis (Figure 2A and B, white bars) showed different biofilm-forming rates for the 3 strains tested. This finding may be due to the quality, quantity, or timing of their adhesin, or extracellular polysaccharide production (Ruas-Madiedo et al., 2005; Vuong et al., 2005).

\section{Effects of Association on Pseudomonas}

Figure 1 shows that coculture had no significant effect on the planktonic count of Pseudomonas, independently of the size of its own inoculum or that of the strain of L. lactis. Biofilm counts indicated that 2 of the 3 Lactococcus strains enhanced the attachment of Pseudomonas cells by 15- to 100 -fold in the low inoculum cultures (Figure 1A). Pseudomonas enhancement was not proportional to the size of Lactococcus inocula and was highest with the slowest biofilm former, strain 41 , of the L. lactis strains tested.

Images from CSLM (Figure 3) show that in cooperative cocultures of Pseudomonas and L. lactis strain 41, biofilms appeared more compact, and both cell types were close together. Spatial arrangement of consortia partners in biofilms (as seen by CSLM) relates to the type of ecological relationship existing between them. Shorter distances between different microcolonies or mixed-cell patterns usually correspond to positive interactions (Cowan et al., 2000; Nielsen et al., 2000) as in Figure 3 (strain 41).

Pseudomonas in cold milk are known to produce extracellular proteinases after they reach $10^{5}$ to $10^{6} \mathrm{cfu} /$ $\mathrm{mL}$ (Matta et al., 1997). Below this level, they are short of utilizable $\mathrm{C}$ and $\mathrm{N}$ sources, but proximity to Lactococcus (as in biofilms) could potentially relieve that short- 

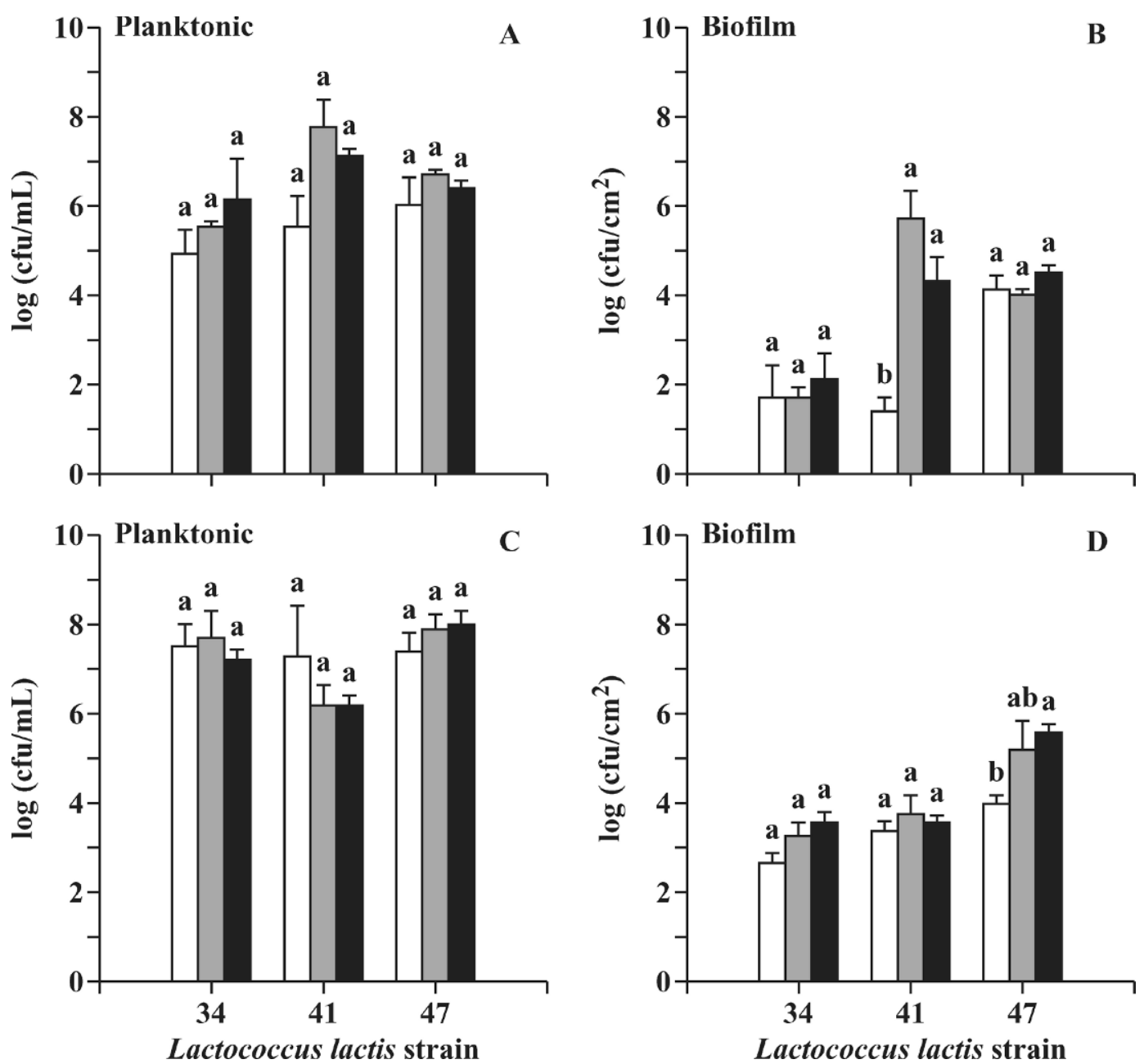

Figure 2. Lactococcus lactis (strains 34,41 , or 47) counts (in UHT milk $7^{\circ} \mathrm{C}$ for $72 \mathrm{~h}$ ) in pure cultures (white bars), or cocultured with Pseudomonas fluorescens, with either low (gray bars) or high (black bars) inoculum levels. A) Planktonic counts and B) biofilm counts using low inoculum of L. lactis; C) planktonic counts and D) biofilm counts using high inoculum of L. lactis. Error bars represent the confidence interval for the mean $(\mathrm{n}=3)$. ${ }^{\mathrm{a} b}$ Values within the same bar group with different letter are significantly $(P<0.01)$ different.

age. Pseudomonas can use lactic acid as a source of $\mathrm{C}$ and energy (SanJose et al., 1987). In biofilms, it is possible that the rates of lactic acid production (by L. lactis) and consumption (by Pseudomonas) are compensated, preventing $\mathrm{pH}$ decrease. Pseudomonas can also benefit by obtaining extra nutrients from autolysis of the lactococci (Garde et al., 2002). Phillips et al. (1983) found that nisin added to pasteurized double cream increased proteolysis due to fluorescent pseudomonads, thereby improving their growth rate. Jaspe et al. (1995a) reported an improvement in planktonic Pseudomonas growth due to a cheese-making starter containing $L$. lactis.

Most reports on relationships between lactic acid bacteria and Pseudomonas, or other psychrotrophic gramnegative bacteria in milk and dairy products, deal with attempts to antagonize the psychrotrophs for biopreser- vation purposes (Champagne et al., 1994). Required levels of lactic acid bacteria needed to obtain that interference, however, are usually above $10^{6} \mathrm{cfu} / \mathrm{mL}$. On the contrary, the cooperative effect reported herein relies on both low initial populations and simultaneous growth.

\section{Effects of Association on Lactococcus}

Coculture did not have a significant quantitative effect on planktonic growth of the lactococci (Figure 2A and $\mathrm{C}$ ) and the outcome on biofilm cell density depended on both inocula size and Lactococcus strain. In binary cultures with a large $\left(10^{5} \mathrm{cfu} / \mathrm{mL}\right)$ inoculum of strain 47 (Figure 2D), attached lactococci increased by 15 -fold (with low Pseudomonas inoculum) and 40-fold (with high Pseudomonas inoculum), compared with the corresponding monocultures. The more outstanding stimu- 

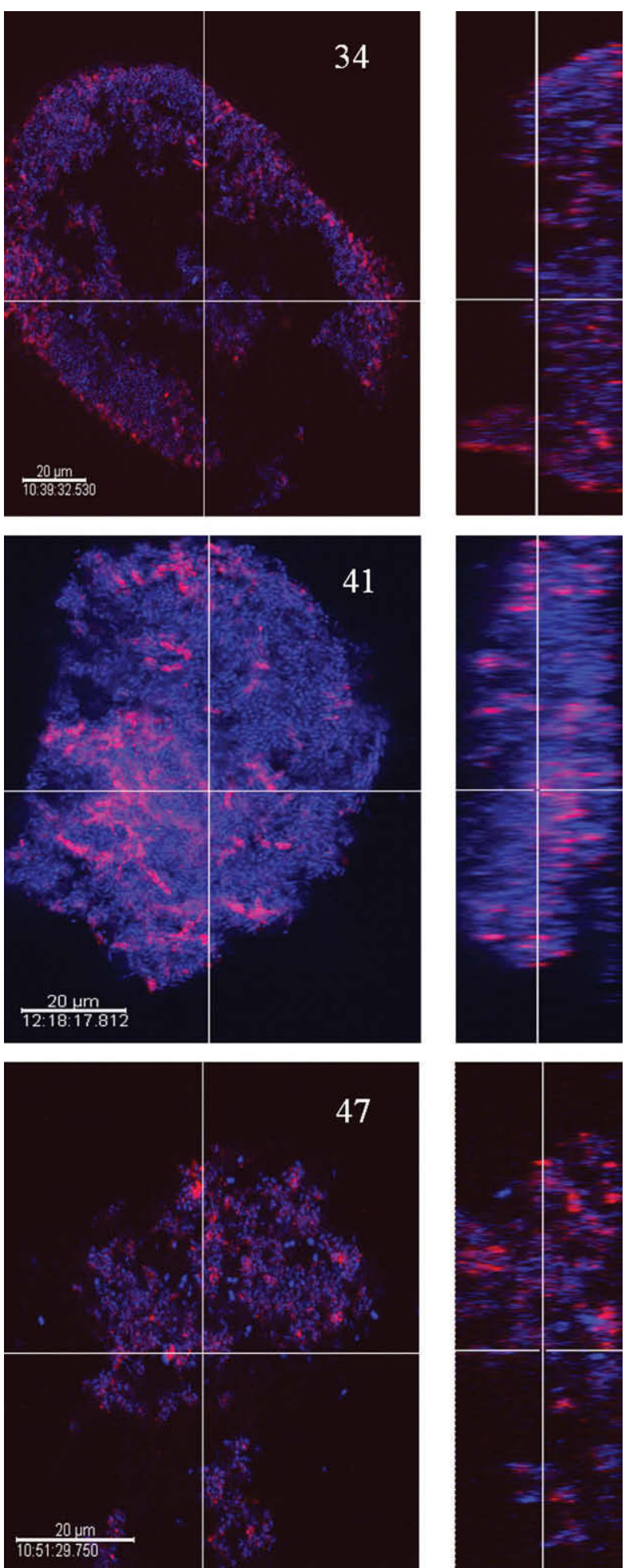

Figure 3. Confocal scanning laser microscopy images of horizontal (left) and vertical (right) sections of mixed biofilms of Pseudomonas fluorescens (blue) and Lactococcus lactis (red). Counts were for $L$. lactis strain $34,4.0 \times 10^{3} \mathrm{cfu} / \mathrm{cm}^{2}$ with $2.5 \times 10^{6} \mathrm{cfu} / \mathrm{cm}^{2}$ of Pseudomonas; for strain $41,6.3 \times 10^{3} \mathrm{cfu} / \mathrm{cm}^{2}$ with $1.0 \times 10^{6} \mathrm{cfu} / \mathrm{cm}^{2}$ of Pseudomonas; and for strain $47,4.0 \times 10^{5} \mathrm{cfu} / \mathrm{cm}^{2}$ with $7.9 \times 10^{6} \mathrm{cfu} / \mathrm{cm}^{2}$ of $P$ seudomonas. lus, however, was observed in binary cultures with low $\left(10^{3} \mathrm{cfu} / \mathrm{mL}\right)$ inoculum of strain 41 , in which their attached cells increased by 20,000-fold due to the association with a low Pseudomonas inoculum (Figure 2B). Because L. lactis strain 41 is a poor biofilm former by itself, one possibility is that $P$. fluorescens enhanced lactococcal strain attachment by providing a quickly developed biofilm matrix to host it. Meanwhile, the fast growth of $P$. fluorescens likely consumed much of the available oxygen inside the biofilms. The resulting anaerobic conditions may stimulate the growth of the lactococcal strain. The lactic acid produced by the lactococcal strain, on the other hand, could be used as a $\mathrm{C}$ source by the Pseudomonas located at the biofilm's surface. However, strains 34 and 47 are also poor biofilm formers and anaerobes, but do not benefit from $P$. fluorescens association, suggesting factors other than the anaerobic condition may be involved in the observed growth enhancement.

Besides lactococci, cases of Pseudomonas favoring the growth of other types of bacteria in the same biofilm have been reported for Listeria monocytogenes (Sasahara and Zottola, 1993), Lactobacillus amylophilus and Lactobacillus casei (Demirci et al., 1993), Bacillus cereus (Lindsay et al., 2002), and Acinetobacter (Christensen et al., 2002).

\section{Ecological Interactions and Relevance for Milk Quality}

Different types of interactions were observed in these binary cultures, depending on planktonic or biofilm phase, initial population of each partner, and L. lactis strain. Protocooperation was the most remarkable of all, occurring only in biofilms of cocultures with low inocula levels and strain 41 . The other detected interactions, all in biofilms, corresponded to cases of commensalism, in which growth rates of either Lactococcus or Pseudomonas (but not both simultaneously) benefited from the association.

Low population levels of Pseudomonas and lactococci are common in good quality raw milk (Desmasures et al., 1997), but it is unknown how prevalent are the strains behaving as strain number 41 are among $L$. lactis ssp. cremoris present in raw milk samples. If they were in relatively high proportion, biofilms at the milking and storage equipment walls should be carefully controlled to avoid proteolytic and lipolytic Pseudomonas-induced defects. In addition, competition could take place between starter strains and wild lactococci established in the biofilms.

As expected, most of the positive interactions observed in this study took place in biofilms from cultures with low inoculum levels of both types of bacteria. An 
exception was L. lactis strain 47 , which obtained a better outcome from the association with Pseudomonas when its own inoculum was high (Figure 2D). This finding may suggest that, at low cell densities of both partners, Pseudomonas would be the favored commensal (as in Figures 1 and 2B), whereas at more advanced growth stages, strain 47 would take over that role (as in Figure 2D).

Although positive interactions probably have a higher chance to occur in young biofilms, other types of relationships could take place, at least transiently. Early settlers on a surface might select their incoming neighbors, checking compatibility on arrival. Carpentier and Chassaing (2004) assessed 29 bacterial isolates from food industry premises as possible biofilm hosts for Listeria monocytogenes incorporated later, finding both positive and negative interactions at early attachment stages.

Mixed cultures with high population densities are more likely to engage in interference competition. Both partners studied here are well known for their antagonistic resources. Pseudomonas fluorescens are exploited as biocontrol agents against plant pathogens, and lactic acid bacteria are used as probiotics, starters for making fermented products, or food biopreservation agents. The presence of some of the antagonistic or virulence-related exoproducts of Pseudomonas seems to be associated with transition to stationary phase (Heeb et al., 2005) or quorum sensing (Wagner et al., 2004). An apparently neutral growth outcome (e.g., Figures 1A, C, and $\mathrm{D}$ and $2 \mathrm{~A}$ and $\mathrm{C}$ ) could correspond to a balanced situation with both cooperative and competitive aspects.

It is important to note that these results were obtained at $7^{\circ} \mathrm{C}$. Pseudomonas expresses a different phenotype at refrigeration temperatures (Regeard et al., 2000 ). Its production of extracellular gluconate (Lynch and Franklin, 1978), proteinase (Jaspe et al., 1995b), and cytotoxic agents (Picot et al., 2004) has been found to be greater at 7 to $8^{\circ} \mathrm{C}$ than at higher temperatures. Interference of planktonic Listeria monocytogenes (Farrag and Marth, 1989) and Escherichia coli (Samelis and Sofos, 2002) by Pseudomonas strains has also been reported to be temperature-dependent.

Low counts of wild psychrotrophic strains of $L$. lactis ssp. cremoris and $P$. fluorescens in milk can positively interact during cold storage, causing an increase in the cell numbers of both species at biofilms without significant effect on planktonic counts or milk $\mathrm{pH}$. As these counts and strains are common in raw milk, such rich biofilms could add spoiling organisms into subsequent raw milk batches that come in contact with them, if not adequately removed.

\section{ACKNOWLEDGMENTS}

This work was supported by the Spanish Ministry of Education and Science research grant no. AGL20000725. The authors are grateful to Pedro J. Agudo and to Luis Miguel Alonso of the Center of Microscopy and Cytometry of the Complutense University of Madrid for skilled technical assistance.

\section{REFERENCES}

Carpentier, B., and D. Chassaing. 2004. Interactions in biofilms between Listeria monocytogenes and resident microorganisms from food industry premises. Int. J. Food Microbiol. 97:111-122.

Champagne, C. P., R. R. Laing, D. Roy, A. A. Mafu, and M. W. Griffiths. 1994. Psychrotrophs in dairy products: Their effect and their control. Crit. Rev. Food Sci. Nutr. 34:1-30.

Christensen, B. B., J. A. J. Haagensen, A. Heydorn, and S. Molin. 2002. Metabolic commensalisms and competition in a two-species microbial consortium. Appl. Environ. Microbiol. 68:2495-2502.

Cowan, S. E., E. Gilbert, D. Liepmann, and J. D. Keasling. 2000. Commensal interactions in a dual-species biofilm exposed to mixed organic compounds. Appl. Environ. Microbiol. 66:44814485.

Demirci, A., A. L. Pometto, III, and K. E. Johnson. 1993. Evaluation of biofilm reactor solid support for mixed-culture lactic acid production. Appl. Microbiol. Biotechnol. 38:728-733.

Desmasures, N., F. Bazin, and M. Gueguen. 1997. Microbiological composition of raw milk from selected farms in the Camembert region of Normandy. J. Appl. Microbiol. 83:53-58.

Farrag, S. A., and E. H. Marth. 1989. Growth of Listeria monocytogenes in the presence of Pseudomonas fluorescens at 7 or $13^{\circ} \mathrm{C}$ in skim milk. J. Food Prot. 52:852-855.

Garde, S., P. Gaya, M. Medina, and M. Nuñez. 2002. Autolytic behaviour of Lactococcus lactis subsp. cremoris and L. lactis subsp. lactis wild isolates from ewe's raw milk cheeses. Milchwissenschaft 57:143-147.

Gram, L., L. Ravn, M. Rasch, J. B. Bruhn, A. Christensen, and M. Givskov. 2002. Food spoilage interactions between food spoilage bacteria. Int. J. Food Microbiol. 78:79-97.

Hamasaki, Y., M. Ayaki, H. Fuchu, M. Sugiyama, and H. Morita. 2003. Behavior of psychrotrophic lactic acid bacteria isolated from spoiling cooked meat products. Appl. Environ. Microbiol. 69:3668-3671.

Heeb, S., C. Valverde, C. Gigot-Bonnetoy, and D. Haas. 2005. Role of the stress sigma factor RpoS in Gac/RsmA-controlled secondary metabolism and resistance to oxidative stress in Pseudomonas fluorescens CHA0. FEMS Microbiol. Lett. 243:251-258.

Holm, C., L. Jepsen, M. Larsen, and L. Jespersen. 2004. Predominant microflora of downgraded Danish bulk tank milk. J. Dairy Sci. 87:1151-1157.

Huis in't Veld, J. H. J. 1996. Microbiological and biochemical spoilage of foods: An overview. Int. J. Food Microbiol. 33:1-18.

Jaspe, A., L. Fernandez, P. Palacios, and C. SanJose. 1995a. Interaction between Pseudomonas fluorescens and lactic acid starter Hansen $\mathrm{n}^{\circ} 44$ in milk at $7^{\circ} \mathrm{C}$. Milchwissenschaft 50:607-610.

Jaspe, A., P. Oviedo, L. Fernandez, P. Palacios, and C. SanJose. 1995b. Cooling raw milk: change in the spoilage potential of contaminating Pseudomonas. J. Food Prot. 58:915-921.

Lindsay, D., V. S. Brozel, J. F. Mostert, and A. von Holy. 2002. Differential efficacy of a chlorine dioxide-containing sanitizer against single species and binary biofilms of a dairy-associated Bacillus cereus and a Pseudomonas fluorescens isolate. J. Appl. Microbiol. 92:352-361.

Lynch, W. H., and M. Franklin. 1978. Effect of temperature on the uptake of glucose, gluconate and 2-ketogluconate by Pseudomonas fluorescens. Can. J. Microbiol. 24:56-62.

Matta, H., V. Punj, and S. S. Kanwar. 1997. An inmunodot blot assay for detection of thermostable protease from Pseudomonas sp. AFF36 of dairy origin. Lett. Appl. Microbiol. 25:300-302. 
McKellar, R. C., and H. Cholette. 1984. Synthesis of extracellular proteinase by Pseudomonas fluorescens under conditions of limiting carbon, nitrogen and phosphate. Appl. Environ. Microbiol. 47:1224-1227.

Nielsen, A. T., T. Tolker-Nielsen, K. B. Barken, and S. Molin. 2000. Role of commensal relationships on the spatial structure of a surface-attached microbial consortium. Environ. Microbiol. 2:59-68.

Phillips, J. D., M. W. Griffiths, and D. D. Muir. 1983. Effect of nisin on the shelf-life of pasteurized double cream. J. Soc. Dairy Technol. $36: 17-21$.

Picot, L., S. Mezghani-Abdelmoula, S. Chevalier, A. Merieau, O. Lesouhaitierm, J. Guerillon, L. Cazin, N. Orange, and M. G. J. Feuilloley. 2004. Regulation of the cytotoxic effects of Pseudomonas fluorescens by growth temperature. Res. Microbiol. 155:39-46.

Regeard, C., A. Merieau, and J. F. Guespin-Michel. 2000. A bioluminescence assay for screening thermoregulated genes in a psychrotrophic bacterium Pseudomonas fluorescens. J. Appl. Microbiol. 88:183-189.

Richardson, B. C., and I. E. Te Whaiti. 1978. Partial characterization of heat stable extracellular proteases of some psychrotrophic bacteria from raw milk. N.Z. J. Dairy Sci. Technol. 13:172-176.

Ruas-Madiedo, P., A. C. Alting, and P. Zoon. 2005. Effect of polysaccharides and proteolytic activity of Lactococcus lactis subsp. cremoris strains on the viscosity and structure of fermented milks. Int. Dairy J. 15:155-164.

Samelis, J., and J. N. Sofos. 2002. Role of glucose in enhancing the temperature-dependent growth inhibition of Escherichia coli
O157:H7 ATCC 43895 by a Pseudomonas sp. Appl. Environ. Microbiol. 68:2600-2604.

SanJose, C., L. Fernandez, and P. Palacios. 1987. Compositional changes in cold raw milk supporting growth of Pseudomonas fluorescens NCDO 2085 before production of extracellular proteinase. J. Food Prot. 50:1004-1008.

Sasahara, K. C., and E. A. Zottola. 1993. Biofilms formation by Listeria monocytogenes utilizes a primary colonizing microorganism in flowing systems. J. Food Prot. 56:1022-1028.

Somers, E. B., M. E. Johnson, and A. C. L. Wong. 2001. Biofilm formation and contamination of cheese by non-starter lactic acid bacteria in the dairy environment. J. Dairy Sci. 84:1926-1936.

Sørhaug, T., and L. Stepaniak. 1997. Psychrotrophs and their enzymes in milk and dairy products: Quality aspects. Trends Food Sci. Technol. 8:35-41.

Stoodley, P., K. Sauer, D. G. Davies, and J. W. Costerton. 2002. Biofilms as complex differentiated communities. Annu. Rev. Microbiol. 56:187-209.

Vuong, C., J. B. Kidder, E. R. Jacobson, M. Otto, R. A. Proctor, and G. A. Somerville. 2005. Staphylococcus epidermidis polysaccharide intercellular adhesion production significantly increases during tricarboxylic acid cycle stress. J. Bacteriol. 187:2967-2973.

Wagner, V. E., R. J. Gillis, and B. Iglewski. 2004. Transcriptome analysis of quorum-sensing regulation and virulence factor expression in Pseudomonas aeruginosa. Vaccine 22S:515-520.

Wong, A. C. L., and O. Cerf. 1995. Biofilms: Implications for hygiene monitoring of dairy plant surfaces. Bull. IDF 302:40-44. 